\title{
Incidence of Anaphylaxis Recorded During 1 Year by the Municipal Emergency Service of Madrid (SAMUR-PC)
}

Gómez-Soler R ${ }^{1}$, Caballero $\mathrm{ML}^{2}$

${ }^{1}$ Urban Emergency Service of Madrid, SAMUR-Civil Protection, Madrid, Spain

${ }^{2}$ Department of Allergy, Hospital La Paz Institute for Health Research (IdiPAZ), Madrid, Spain

J Investig Allergol Clin Immunol 2018; Vol. 28(6): 438-440 doi: $10.18176 /$ jiaci.0315

Key words: Allergy. Epinephrine. Ambulance. Anaphylaxis, Prehospital.

Palabras clave: Alergia. Epinefrina. Ambulancia. Anafilaxia. Prehospitalario.

The European Academy of Allergy and Clinical Immunology defines anaphylaxis as a severe, potentially life-threatening systemic hypersensitivity reaction that is characterized by rapid onset with life-threatening respiratory and/or circulatory problems. It is usually, although not always, associated with skin and mucosal changes [1].

The results of 10 European studies suggested an incidence of anaphylaxis of 1.5-7.9 episodes per 100000 person-years, and, based on 3 of the studies, prevalence was estimated at $0.3 \%(95 \% \mathrm{CI}, 0.1-0.5)$, with foods as the most frequent cause in children and drugs and hymenoptera venom in adults [2]. In our area, the incidence of anaphylaxis among the general population attended in the emergency department (ED) of Hospital Universitario Fundación Alcorcón, Alcorcón (Madrid), Spain was 103.37 episodes per 100000 person-years [3]. In an observational study of patients aged more than 15 years attended in the ED of Hospital General Universitario Gregorio Marañón, Madrid, Spain, the incidence of anaphylaxis was $0.08 \%$, with drugs as the main cause (41.7\%), followed by food (25\%) [4]; the incidence of pediatric anaphylaxis was $0.12 \%$, with food allergy as the cause in $90 \%$ of cases [5].

Our aim was to determine the incidence of anaphylactic reactions attended during 1 year by first aiders in the ambulances of the Municipal Emergency Service of Madrid (SAMUR-PC) and identify their origin based on data provided by patients or witnesses.

We performed a retrospective study of patients attended by advanced life support units of the SAMUR-PC prehospital emergency service and diagnosed with allergic/anaphylaxis over a 1-year period (2016). Data were collected directly from the clinical report for each case, and the variables studied were as follows: demographics, previous allergies, etiology, symptoms, vital signs, treatment, and hospital admission. The data were analyzed using SPSS Statistics for Windows v.17.0 (SPSS Inc). We first analyzed the sample and its clinical features to describe the distribution of each variable in percentages and then performed a multivariate analysis 
using contingency tables and the Pearson $\chi^{2}$ test to compare the association between anaphylaxis (involvement of 2 or more systems) and each of the variables.

A total of 377 of the 111542 incidents attended by the SAMUR-CP service during 2016 were coded as allergy/ anaphylaxis under the International Classification of Diseases, Ninth Revision, Clinical Modification (ICD-9-CM), that is, an incidence of $0.34 \%$. The median age of the patients was 30 years (1-85), $193(51.19 \%)$ were females, and $95(25.19 \%)$ were children $\leq 16$ years. For $186(49.33 \%)$ patients, this was their first allergic reaction (Table). As for etiology, the most frequent trigger in both children and adults was food, with a total of 179 cases $(47.48 \%)$ ). Other relevant triggers in adults were medication (42 cases [14.89\%]), insect sting (14 cases [4.96\%]), and physical exercise (13 cases [4.60\%]). Finally, for both children and adults, a total of 115 cases $(30.50 \%)$ were of unknown etiology (idiopathic).

The most frequent mainfestations in children and adults were cutaneous symptoms (erythema, urticaria, pruritus, angioedema) in 311 patients $(82.49 \%)$, followed by respiratory symptoms (dyspnea, stridor, laryngeal edema) in 77 patients $(20.42 \%$ ), gastrointestinal symptoms (uvular edema, vomiting, dysphagia, discomfort in the oral cavity) in 63 patients $(16.71 \%)$, cardiovascular symptoms (syncope) in 31 patients $(8.22 \%)$, and neurological symptoms in 3 patients $(0.79 \%)$. Furthermore, 96 of the 377 cases of allergy/ anaphylaxis $(25.46 \%)$ were anaphylactic reactions, defined as a hypersensitivity reaction associated with respiratory and/or circulatory compromise or the involvement of 2 or more systems, that is, an incidence of $0.09 \%$ of the 111542 incidents attended.

In these 96 cases of anaphylaxis, food was also the main trigger for both children and adults, with a total of 55 cases $(57.29 \%)(P<.01)$, followed by unknown causes, with 17 cases $(17.70 \%)(P<.01)$. The most frequent manifestations in both children and adults were cutaneous symptoms in 90 patients $(93.75 \%)(P<.01)$, followed by respiratory symptoms in 55 patients $(57.29 \% ; P=0$; OR, 14.42 [8.01-25.93]), gastrointestinal symptoms in 36 patients $(37.50 \% ; P=0$; OR, $6.70[3.75-11.97])$, and cardiovascular symptoms in 23 patients (23.95\%; $P=0$; OR, 10.75; [4.61-25.02]). Finally, a total of 12 patients $(12.50 \%)$ received intramuscular epinephrine $(P<.01)$, and $54(56.25 \%)$ required hospitalization $(P<.01)$.

The incidence of allergic reactions in the specific scenario of a municipal emergency service has previously been investigated in a retrospective study performed by paramedics and first aiders of the Greater Manchester branch of the North West Ambulance Service in the United Kingdom. Over a 12-month period, the authors analyzed the frequency, severity, and outcome of calls, as well as whether intramuscular epinephrine was administered to ensure successful management of anaphylaxis [6]. The results of the study showed that 816 of the 401,152 incidents attended $(0.2 \%)$ were due to allergic reactions and that in 457 patients $(56 \%)$, the reaction was their first allergic reaction. Food caused $63 \%$ of allergic reactions in children, while medication was the most common cause in adults $(62 \%)$, followed by food, which caused $18 \%$ of the reactions. Finally, intramuscular epinephrine was administered to $14 \%$ of patients. The figures
Table. Clinical Features of the Total Cohort of Allergy/Anaphylaxis Cases Registered by the SAMUR-CP Service During the 1-Year Study Period

\begin{tabular}{|c|c|c|c|}
\hline & $\begin{array}{c}\text { Anaphylaxis } \\
n=96\end{array}$ & $\begin{array}{l}\text { Other reactions } \\
\qquad \mathrm{n}=281\end{array}$ & $\begin{array}{c}\text { Total } \\
\mathrm{N}=377\end{array}$ \\
\hline $\begin{array}{l}\text { First allergic } \\
\text { reaction }\end{array}$ & $46(47.91 \%)$ & $140(49.82 \%)$ & $186(49.33 \%)$ \\
\hline Previous allergy & $50(52.08 \%)$ & $141(50.17 \%)$ & $191(50.66 \%)$ \\
\hline \multicolumn{4}{|l|}{ Triggers } \\
\hline Food & $\begin{array}{c}55(57.29 \%) \\
(P<.01)\end{array}$ & $124(44.12 \%)$ & $179(47.48 \%)$ \\
\hline Unknown & $\begin{array}{c}17(17.70 \%) \\
(P<.01)\end{array}$ & $98(34.87 \%)$ & $115(30.50 \%)$ \\
\hline Medication & $14(14.58 \%)$ & $30(10.67 \%)$ & $44(11.67 \%)$ \\
\hline Insect sting & $2(2.08 \%)$ & $14(4.98 \%)$ & $16(4.24 \%)$ \\
\hline Physical exercise & $4(4.16 \%)$ & $9(3.20 \%)$ & $13(3.44 \%)$ \\
\hline Contrast media & $0(0 \%)$ & $2(0.71 \%)$ & $2(0.53 \%)$ \\
\hline Occupational & $0(0 \%)$ & $1(0.35 \%)$ & $1(0.26 \%)$ \\
\hline \multicolumn{4}{|l|}{ Symptoms } \\
\hline Cutaneous & $\begin{array}{c}90(93.75 \%) \\
(P<.01)\end{array}$ & $221(78.64 \%)$ & $311(82.49 \%)$ \\
\hline Respiratory & $55(57.29 \%)$ & $22(7.82 \%)$ & $77(20.42 \%)$ \\
\hline Gastrointestinal & $36(37.50 \%)$ & $27(9.60 \%)$ & $63(16.71 \%)$ \\
\hline Cardiovascular & $23(23.95 \%)$ & $8(2.84 \%)$ & $31(8.22 \%)$ \\
\hline Neurological & $1(1.04 \%)$ & $2(0.71 \%)$ & $3(0.79 \%)$ \\
\hline Anaphylaxis & 96 & & $96(25.46 \%)$ \\
\hline \multicolumn{4}{|l|}{ Treatment received } \\
\hline $\begin{array}{l}\text { Self-administered } \\
\text { epinephrine }\end{array}$ & d $4(4.16 \%)$ & $0(0 \%)$ & $4(1.06 \%)$ \\
\hline Epinephrine & $\begin{array}{c}12(12.50 \%) \\
(P<.01)\end{array}$ & $9(3.20 \%)$ & $21(5.57 \%)$ \\
\hline Hospitalization & $\begin{array}{c}54(56.25 \%) \\
\quad(P<.01)\end{array}$ & $91(32.38 \%)$ & $145(38.46 \%)$ \\
\hline
\end{tabular}

for incidence of allergy/anaphylaxis and for administration of epinephrine reported in this study are consistent with those observed in our study. However, our results showed food to be the main cause of allergy/anaphylaxis and anaphylactic reactions in both children and adults.

We highlight the fact that the triggers registered as being responsible for the reactions were suspected triggers, because they were obtained from the information in the clinical history but were not confirmed with an allergy study, given that subsequent follow-up of patients is not possible for SAMURPC. Consequently, values could vary, and figures for idiopathic allergy/anaphylaxis (30.50\%) and anaphylaxis (17.70\%) could prove to be lower after an allergy work-up $[4,5,7,8]$.

On the other hand, since $I C D-9$ codes have been proven to be insufficient for detecting all cases of anaphylaxis [9], the 
figure of anaphylaxis could be higher. This could be a major bias of our study.

In conclusion, allergy and anaphylaxis account for $0.34 \%$ of the incidents attended in a year by the SAMUR-PC service. Food is the main trigger of the reactions in both children and adults according to the data recorded.

\section{Funding}

The authors declare that no funding was received for the present study.

\section{Conflicts of Interest}

The authors declare that they have no conflicts of interest.

\section{Previous Presentations}

This study was presented in poster form (P-1932) at the 29th National Congress of the Spanish Society of Emergency, which was held in Alicante, June 7-9, 2017

\section{References}

1. Muraro A, Roberts $G$, Worm M, Bilo MB, Brockow $K$, Fernandez-Rivas $M$, et al. Anaphylaxis: guidelines from the European Academy of Allergy and Clinical Immunology. Allergy. 2014;69:1026-45.

2. Panesar SS, Javad S, De Silva D, Nwaru BI, Hickstein L, Muraro A, et al. The epidemiology of anaphylaxis in Europe: a systematic review. Allergy. 2013;68:1353-61.

3. Tejedor Alonso MA, Moro Moro M, Múgica García MV, Esteban Hernández J, Rosado Ingelmo A, Vila Albelda C, et al. Incidence of anaphylaxis in the city of Alcorcon (Spain): a population-based study. Clin Exp Allergy. 2012;42:578-89.

4. Alvarez-Perea $A$, Tomás-Pérez $M$, Martínez-Lezcano $P$, Marco $G$, Pérez D, Zubeldia JM, et al. Anaphylaxis in Adolescent/Adult Patients Treated in the Emergency Department: Differences Between Initial Impressions and the Definitive Diagnosis. J Investig Allergol Clin Immunol. 2015;25:288-94.

5. Alvarez-Perea A, Ameiro B, Morales C, Zambrano G, Rodríguez A, Guzmán $M$, et al. Anaphylaxis in the Pediatric Emergency Department: Analysis of 133 Cases After an Allergy Workup. J Allergy Clin Immunol Pract. 2017;5:1256-63.

6. Capps JA, Sharma V, Arkwright PD. Prevalence, outcome and pre-hospital management of anaphylaxis by first aiders and paramedical ambulance staff in Manchester, UK. Resuscitation. 2010;81:653-7.

7. Campbell RL, Park MA, Kueber MA Jr, Lee S, Hagan JB. Outcomes of allergy/immunology follow-up after an emergency department evaluation for anaphylaxis. J Allergy Clin Immunol Pract. 2015;3:88-93.

8. Oropeza AR, Bindslev-Jensen C, Broesby-Olsen S, Kristensen T, Møller MB, Vestergaard $H$, et al. Patterns of anaphylaxis after diagnostic workup: A follow-up study of 226 patients with suspected anaphylaxis. Allergy. 2017;72:1944-52.
9. Trojan $T, M a ~ Y$, Khan DA. Anaphylaxis identification using direct and combined ICD-9 methods. J Allergy Clin Immunol. 2013;131:AB224.

Manuscript received May 24, 2018; accepted for publication September 3, 2018

María Luisa Caballero

Department of Allergy Hospital La Paz Institute for Health Research (IdiPAZ) Madrid, Spain E-mail: mlcsoto@hotmail.com 